\title{
High Rate of Multidrug-resistance Among Clinical Isolates of Gram-negative Bacteria in Hospitalized Patients With Febrile Diseases in Central Ethiopia
}

Tafese B Tufa ( $\square$ tafeseb.tufa@yahoo.com)

Arsi University College of Health Sciences and Hirsch Institute of Tropical Medicine https://orcid.org/0000-0002-9505-9341

Colin R Mackenzie

Institute of Medical Microbiology and Hospital Hygiene, University Hospital Duesseldorf, Medical Faculty, Heinrich Heine University, Universitätsstr. 1, 40225,

Duesseldorf

Hans Martin Orth

Department of Gastroenterology, Hepatology and Infectious Diseases, University Hospital Duesseldorf, Medical Faculty, Heinrich Heine University, Moorenstr. 5, 40225, Duesseldorf

Tobias Wienemann

Institute of Medical Microbiology and Hospital Hygiene, University Hospital Duesseldorf, Medical Faculty, Heinrich Heine University, Universitätsstr. 1, 40225, Duesseldorf

Tamara Nordmann

University Medical Center Hamburg-Eppendorf, 1. Department of Medicine, Division Tropical Medicine, Bernhard-Nacht-Straße 74, 20359 Hamburg

Sileshi Abdissa

College of Health Sciences, Arsi University, P.O. Box 04, Asella

Zewdu Hurissa

College of Health Sciences, Arsi University, P.O. Box 04, Asella

Andreas Schönfeld

Department of Infectious Diseases, Essen University Hospital, University of Duisburg-Essen, Essen

Matthias Bosselmann

Hirsch Institute of Tropical Medicine, P.O. Box 04, Asella

Dieter Häussinger

Department of Gastroenterology, Hepatology and Infectious Diseases, University Hospital Duesseldorf, Medical Faculty, Heinrich Heine University, Moorenstr.

5, 40225, Duesseldorf

Klaus Pfeffer

Institute of Medical Microbiology and Hospital Hygiene, University Hospital Duesseldorf, Medical Faculty, Heinrich Heine University, Universitätsstr. 1, 40225,

Duesseldorf

Tom Luedde

Department of Gastroenterology, Hepatology and Infectious Diseases, University Hospital Duesseldorf, Medical Faculty, Heinrich Heine University, Moorenstr. 5, 40225, Duesseldorf

Andre Fuchs

Internal Medicine III - Gastroenterology and Infectious Diseases, University Hospital of Augsburg, Stenglinstr. 2, 86156 Augsburg

Torsten Feldt

Department of Gastroenterology, Hepatology and Infectious Diseases, University Hospital Duesseldorf, Medical Faculty, Heinrich Heine University, Moorenstr. 5, 40225, Duesseldorf

\section{Research}

Keywords: Antimicrobial resistance, CTX-M-1, TEM, NDM-1, ESBL, ESBL genes, carbapenemase, sub-Saharan Africa

Posted Date: July 30th, 2021

DOI: https://doi.org/10.21203/rs.3.rs-743318/v1

License: @) (1) This work is licensed under a Creative Commons Attribution 4.0 International License. Read Full License 


\section{Abstract}

Background

Infectious diseases are among the leading causes of death in many low-income countries such as Ethiopia. Without reliable local data concerning causative pathogens and antimicrobial resistance, empirical treatment is suboptimal. The objective of this study was the characterization of Gram-negative bacteria (GNB) as pathogens and their resistance pattern in hospitalized patients with infections in Central Ethiopia.

\section{Methods}

Patients $\geq 1$ year of age with fever admitted to the Asella Referral and Teaching Hospital from April 2016 to June 2018 were included. Blood and other appropriate clinical specimens were collected and cultured on appropriate media. Antibiotic susceptibility testing (AST) was performed using the Kirby-Bauer method and VITEK ${ }^{\circledR}$ 2. Species identification and detection of resistance-genes were conducted using MALDI-ToF-MS (VITEK ${ }^{\circledR}$ MS) and PCR respectively.

\section{Results}

Of 684 study participants, $54.2 \%$ were male and median age was 22.0 (IQR: 14-35) years. Blood cultures were positive in 5.4\% ( $n=37$ ). In other clinical samples, cultures were positive in $60.6 \%(20 / 33), 20.8 \%(5 / 24)$, and $37.5 \%(3 / 8)$ in swabs/pus, urine and other body fluids, respectively. Of 66 pathogenic isolates, $57.6 \%(\mathrm{n}=38)$ were GNB, $(39.4 \%(\mathrm{n}=26)$ Gram-positive and $3.0 \%(\mathrm{n}=2)$ were candida species. Among the isolated GNB, $42.1 \%(16 / 38)$ were $E$. coli, $23.7 \%$ (9/38) K. pneumoniae and 10.5\% (4/38) P. aeruginosa.

In total, $27 / 38$ Gram-negative isolates were available for further analysis. Resistance rates were: ampicillin/sulbactam $92.6 \%$ ( $n=25)$, cefotaxime $88.9 \%$ ( $n=24)$, ceftazidime 74.1\% ( $n=20)$, cefepime 74.1\% ( $n=20)$, gentamicin 55.6\% ( $n=15)$, piperacillin/tazobactam 48.1\% ( $=13)$, meropenem 7.4\% ( $n=2)$, and amikacin $3.7 \%(n=1)$. The NDM-1 gene was detected in one K. pneumoniae and one A. baumannii isolate, which carried an additional OXA-51 gene. Genes for ESBLs were detected in 81.5\% ( $n=22)$ isolates as follows: TEM 77.2\% ( $n=17)$, CTX-M-1-group 68.2\% ( $n=15)$, SHV-group 27.3\% ( $=6$ ) and CTX-M-9-group 9.1\% ( $=2$ ). Clinical treatment data revealed ineffective antimicrobial treatment in 13 of 18 (72.2\%) patients.

\section{Conclusion}

We report a high prevalence of ESBL-producing bacteria (81.5\%) and carbapenem-resistance (7.4\%), with more than half of the GNB carrying two or more ESBL genes resulting in sub-optimal empiric antibiotic therapy. These findings indicate a need for local and national antimicrobial resistance surveillance and strengthening of antimicrobial stewardship programs.

\section{Introduction}

Infectious diseases are among the leading causes of morbidity and mortality in many low-income countries such as Ethiopia (1). Bacteremia and sepsis are common and are severe complications of many different infections caused by GNB leading to high rates of mortality. Pneumonia, bacteremia, urinary tract infection, intra-abdominal infection and skin and soft tissue infection are the major GNB source of infections (2).

The emerging multi-drug resistance (MDR) in Gram-negative bacteria (GNB) has become a serious public health problem across the world (3). A major driver of resistance in GNB is the horizontal transfer of mobile genetic elements (MGE) carrying genes for extended-spectrum $\beta$-lactamases (ESBL) and/or carbapenemases (4). These enzymes hydrolyze penicillins, third generation cephalosporins (3GC) and carbapenems respectively. The most common ESBL genes are CTX-M-type (cefotaximase), TEM (Temoneira), and SHV (sulfhydryl reagent variable), whereas the most prevalent carbapenemase-encoding genes were OXA (oxacillinase), KPC (Klebsiella pneumoniae) and MBL (metallo beta-lactamase) such as NDM (New Delhi metallo- $\beta$-lactamase), IMP (imipenemase) and Verona imipenemase (VIM), which confer resistance to cephalosporins and carbapenems $(5,6)$.

Despite evidence for high rates of 3GC-reistance among Gram-negative isolates in many African countries of around 50\%, 3GCs are among the most commonly used antibiotics for the initial empiric treatment of severe infections and sepsis in sub-Saharan Africa. Data to estimate the mortality associated with antimicrobial resistance (AMR) in sub-Sahara African countries is limited (7). Rapid interventions such as the establishment of antimicrobial stewardship (AMS) programs, strengthening of antimicrobial susceptibility testing (AST) capacity, revision and updating of existing management protocols of infectious diseases and provision of local and national AMR data for common bacterial pathogens should have a high priority. Continued extensive empiric use of $3 G \mathrm{C}$ in the absence of AST might lead to a further decrease in antimicrobial activity and therefore increase the burden on resource-limited health care systems of the countries affected (8). This development can also be observed locally and previous investigations at the study site show that the effectiveness of the limited choice of available antimicrobials is diminished due to the high rate of ESBL-producing GNB (9). There is an increasing need for strategies to enhance prudent use of antibiotics in the country due to the alarming spread of ESBL-producing GNB leading to high rates of infections due to MDR, which are difficult if not impossible to treat $(10,11)$.

The lack of systematically acquired local data concerning both the causative organisms and common resistance patterns results in ineffective empirical treatment and an unfavorable clinical outcome. Therefore, we assessed the rate and extent of drug resistance among GNB isolated from hospitalized patients with acute infectious diseases at a tertiary hospital in Central Ethiopia and the pertinent drug resistance genes.

\section{Materials And Methods}

\section{Study design and inclusion}


This prospective operational research was conducted from April 2016 to June 2018 at the Asella Referral and Teaching Hospital (ARTH), a tertiary hospital in the town of Asella, located in the central part of Ethiopia. The bacterial cultures were performed in Ethiopia, the secondary and molecular biological investigations were performed in Germany.

A trained study team identified eligible patients. During the study period, all patients $\geq 1$ year of age presenting for treatment at the ARTH with fever defined as body temperature $>37.5^{\circ} \mathrm{C}$ according to tympanic measurement were offered inclusion in the study. After written informed consent by patients or legal guardians, blood cultures (BC) were drawn from all participants. Previously initiated antibiotic treatment was not an exclusion criterion. In addition to BC, appropriate clinical samples according to the patient's symptoms and the treating physician's decision were collected for further microbiological investigation, according to local standard operating procedures (SOPs) and national treatment guidelines. Socio-demographic and clinical data were collected by using a standardized questionnaire.

\section{Ethical approval and consent to participate}

The appropriate ethical review boards of Arsi University (reference number A/U/H/S/C/120/6443/2017), the Oromia Regional Health Bureau (reference number BEFO/AHBTFH/1-8/2017), and Düsseldorf University Hospital (reference number 5729) approved the study. The ethical clearance for samples transportation between Ethiopia and Germany was obtained from the National Ethical Review Board of the Ministry of Science and Technology (reference number 310/204/2017). Before inclusion in the study, written informed consent to participate in the study was obtained from each participant or, in the case of minors, from their legal guardians.

\section{Blood culture}

From every child and adult participant, between approximately $5 \mathrm{~mL}$ and $10-20 \mathrm{~mL}$ of blood were drawn, and inoculated into an aerobic blood culture bottle (in-house production for the first 200 participants and thereafter commercially available blood culture bottles were used). The culture was incubated at $37^{\circ} \mathrm{C}$ for a maximum period of five days. After 24 hours and at the end of the incubation period, Gram staining and sub-culturing on blood, MacConkey, and chocolate agar in candle jar or a $5 \% \mathrm{CO}_{2}$ enriched atmosphere were performed. Biochemical identification tests were subsequently done based on the Gramstaining result. Due to limited resources, only one aerobic culture was performed per patient. Regular quality controls for sensitivity were performed by incubation of standard laboratory strains of different bacteria.

\section{Urine Culture}

In participants with possible urinary tract infection, mid-stream urine specimens were collected using sterile urine cups and $1 \mu \mathrm{L}$ of the urine was inoculated onto blood and MacConkey agar. After 24 hours incubation at $37^{\circ} \mathrm{C}$, bacterial colonies were further processed if the colony count was $\geq 10^{5} \mathrm{CFU} / \mathrm{mL}$.

\section{Swabs and other body fluid culture}

If appropriate to the participants' complaints, swabs or aspiration of other body fluid were collected using appropriate sterile sampling devices (swabs, sterile syringes etc.) and cultivated on blood and chocolate agar in $5 \% \mathrm{CO}_{2}$ enriched atmosphere. The isolates were further processed following the local laboratory's SOPs.

\section{Antimicrobial susceptibility testing}

Following the identification of Gram-negative bacteria, Kirby-Bauer AST was performed after cultivation on Mueller Hinton Agar. The procedure and interpretation followed the European Committee on Antimicrobial Susceptibility Testing (EUCAST) recommendations. The microbiological result was reported to the treating physicians at the ARTH as soon as possible to ensure appropriate patient care.

\section{Confirmation of species identification and antimicrobial susceptibility test}

Bacterial isolates were preserved at $-80^{\circ} \mathrm{C}$ in Microbank ${ }^{\circledR}$ vials (Pro-Lab Diagnostics Inc., Toronto, Canada). Subsequently, samples of all isolates were exported to Germany for confirmation of species identification and AST as well as molecular biological analysis of resistance mechanisms. Species identification was confirmed by using matrix-assisted laser desorption/ionization-time of flight mass spectrometry (MALDI-TOF, Vitek ${ }^{\circledR}$ MS, bioMérieux, Marcyl'Étoile, France) and the local AST result was confirmed by VITEK ${ }^{\circledR} 2$ (bioMérieux).

\section{ESBL and carbapenemase genes detection}

After identification and AST, DNA of the GNB was extracted by suspending a pure colony grown on MacConkey agar in $200 \mu \mathrm{L}$ of Tris-EDTA pH 8.0 buffer. The suspension was then heated at $95^{\circ} \mathrm{C}$ for $20 \mathrm{~min}$, followed by centrifugation at $10,000 \mathrm{rpm}$ for $10 \mathrm{~min}$. Then, $150 \mu \mathrm{l}$ of the supernatant was transferred into a new tube and stored at $-20^{\circ} \mathrm{C}$ until PCR testing could be performed.

Bacterial strains with suspected production of ESBL or carbapenemase according to the AST result were investigated by PCR. We used the PCR protocols described by Strauß et al. for identification of the $\beta$-lactamase bla $a_{\mathrm{CTX}-\mathrm{M}}$, bla $a_{\mathrm{SHV}}$ and bla $a_{\mathrm{TEM}}$ genes (12) and an in-house PCR protocol established for the detection of the carbapenemase genes $b / a_{\mathrm{NDM}-1}$ and $b / a_{\mathrm{OXA}-51}$, as described by Wendel et al. $(13,14)(\mathrm{Table} 1)$.

\section{Data analysis}


Data were entered and analyzed using IBM SPSS Statistics for Windows version 25 (IBM Corp., Armonk, NY, USA). Fisher's exact and Pearson's chi-squared tests were used for the analysis of quantitative variables and mean, median and standard division were used for continuous variables. Differences were considered statistically significant at $p<0.05$.

Table 1: Oligonucleotide sequences of the primer pairs used for molecular resistance gene detection.

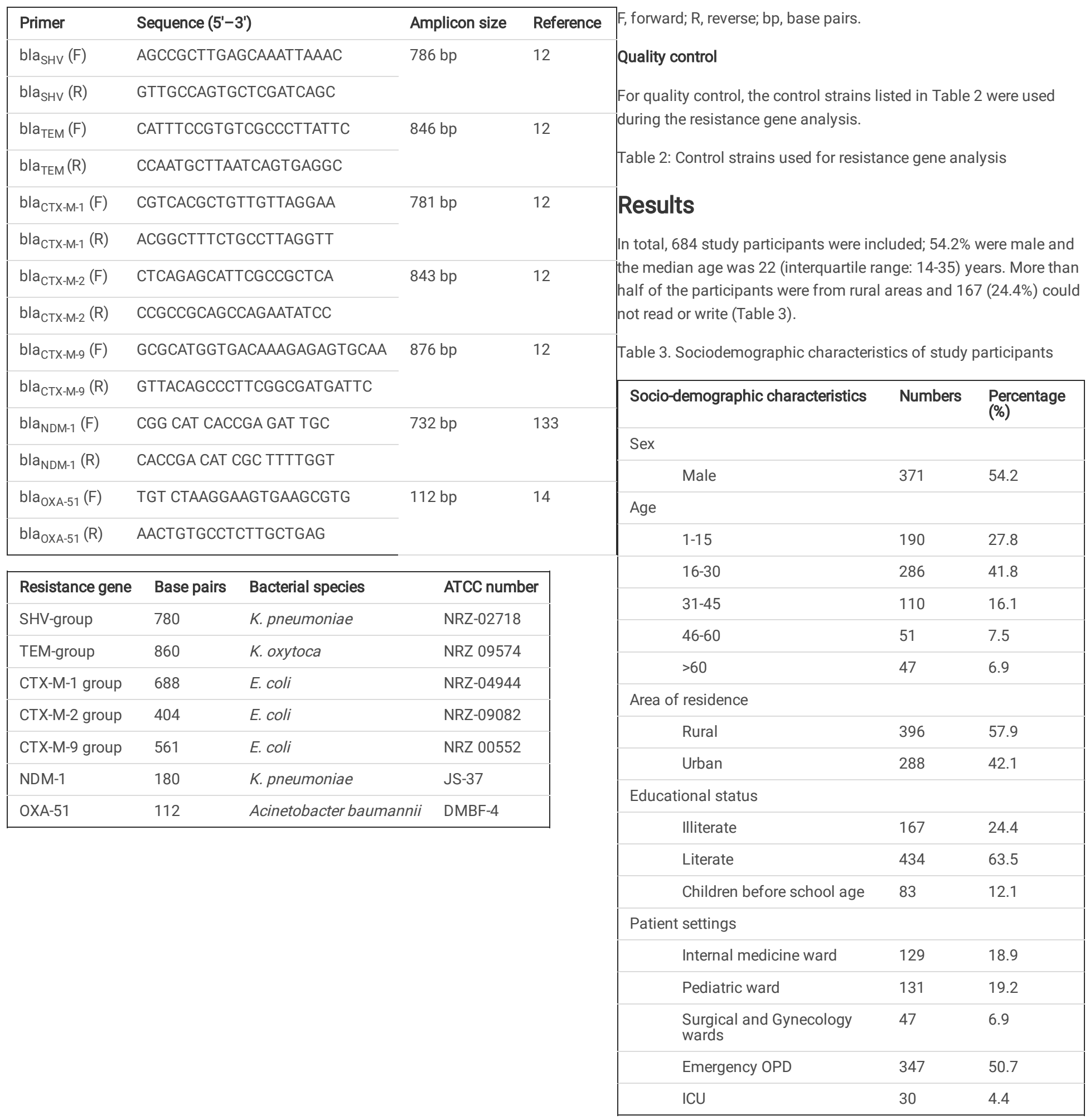

ICU: intensive care unit; OPD: out-patients department

\section{Bacterial cultures}

The overall bacterial detection rate across all sample materials was $12.1 \%(83 / 684)$. In $9.6 \%(n=66)$ the isolated bacterium was considered a pathogen and in $2.5 \%(n=17)$ coagulase-negative staphylococci (CoNS) were isolated and considered as clinically irrelevant because of the high likelihood of contamination. The overall blood culture positivity rate was $5.4 \%(37 / 684)$, among which $51.4 \%(n=19)$ were $\mathrm{GNB}$. The overall detection rate in other clinical samples was 
$60.6 \%$ (20/33), $20.8 \%$ (5/24), and $37.5 \%$ (3/8) in swabs/pus, urine, and other body fluids, respectively. Out of 12 cultured cerebrospinal fluid samples, only one sample revealed growth of a pathogen ( $N$. meningitidis). Overall, 66 pathogenic bacteria were isolated from a total of 761 different clinical samples. Of those, 57.6\% ( $n=38)$ were GNB, 39.4\% ( $n=26)$ Gram-positive and 3\% $(n=2)$ Candida species. S. aureus and E. coli were the most prevalent isolates among Grampositive and Gram-negative isolates, respectively. Among the 38 Gram-negative isolates, $42.1 \%(n=16)$ were E. coli, $23.7 \%(n=9)$ K. pneumoniae, and $10.5 \%$ $(\mathrm{n}=4) P$. aeruginosa (for further details see Table 4).

Table 4. Frequencies of isolated GNB isolates from different clinical samples of the study participants $(n=38)$

\begin{tabular}{|lll|}
\hline Bacterial species & Number & $\%$ \\
\hline E. coli & 16 & 42.1 \\
K. pneumonia & 9 & 23.7 \\
\hline P. aeruginosa & 4 & 10.5 \\
\hline Salmonella typhi & 2 & 5.3 \\
\hline Enterobacter spp. & 2 & 5.3 \\
\hline A. baumannii & 1 & 2.6 \\
\hline N. meningitides & 1 & 2.6 \\
\hline R. ornithinolytica & 1 & 2.6 \\
\hline R. planticola & 1 & 2.6 \\
\hline Serratia spp. & 1 & 2.6 \\
\hline
\end{tabular}

As indicated in Table 5, among all clinical samples bacterial growth was identified significantly more often among patients with skin and soft tissue infections (SSTI) ( $<<0.001)$. Although not statically significant, samples from patients with a leukocyte count $>12,000$ or $<4000$ cells $/ \mu \mathrm{L}$ at the time of sampling tended to be more likely to reveal bacterial growth $(p=0.07)$. On the other hand, blood cultures from patients with the diagnosis of acute febrile illness with unknown source were least likely to reveal bacteremia compared with other symptoms $(p=0.005)$. Being HIV-positive did not have any impact on blood culture positivity rate $(\mathrm{p}=0.85)$. Equally the $\mathrm{C}$-reactive protein (CRP) had no predictive value concerning blood culture positivity (blood culture positive versus blood culture negative, CRP mean $71.7 \mathrm{mg} / \mathrm{L}$ vs. $64.6 \mathrm{mg} / \mathrm{L} ; \mathrm{p}=0.20)$.

Table 5. Culture positivity rate according to clinical diagnosis of source of infection and laboratory parameters among study participants blood

\begin{tabular}{|llll|}
\hline Infectious focus / laboratory parameters & Culture positive $(\mathbf{N}=66)$ & Culture negative $(\mathbf{N}=618)$ & p-value \\
\hline Pneumonia / RTI $(n=165)$ & $\%(n)$ & $\%(n)$ & 0.38 \\
\hline Urinary tract infections $(n=30)$ & $19.7(13)$ & $24.6(152)$ & 0.20 \\
\hline Meningitis / encephalitis $(n=57)$ & $7.6(5)$ & $4.4(25)$ & 0.48 \\
\hline GITI / hepatitis $(n=43)$ & $6.1(4)$ & $8.6(53)$ & 0.94 \\
\hline SSTIs $(n=52)$ & $6.1(4)$ & $6.3(39)$ & $<0.001$ \\
\hline Acute febrile illness with unknown source $(n=264)$ & $22.7(15)$ & $5.3(33)$ & 0.005 \\
\hline Sepsis* $(n=32)$ & $4.5(3)$ & $40.3(249)$ & 0.96 \\
\hline HIV sero-positivity $(n=58)$ & $9.1(6)$ & $4.7(29)$ & 0.85 \\
\hline Leukocytes count $>12,000$ or $<4000 / \mu \mathrm{L}(\mathrm{n}=218)$ & $42.4(28)$ & $8.4(52)$ & 0.07 \\
\hline
\end{tabular}

RTIs: Respiratory tract infection, SSTI = skin and soft tissue infection; GITI= gastrointestinal tract infection, CRP=C-reactive protein

* According to clinician's diagnosis, regardless of the focus of the infection

Regarding culture positivity rate among different clinical samples, there was no significant difference between the positivity rates of Gram-positive or Gramnegative isolates. See Table 6 for details.

Table 6. Culture positivity rate among the different clinical samples 


\begin{tabular}{|llll|}
\hline Clinical sample & Culture negative & Culture positive & \\
\cline { 2 - 4 } & & Gram-negative isolate \% $(\mathrm{n})$ & Gram-positive isolate \% $(\mathrm{n})$ \\
\hline All samples $(\mathrm{n}=761)$ & $91.3(695)$ & $5.0(38)$ & $3.7(28)$ \\
\hline Blood $(\mathrm{n}=684)$ & $94.6(647)$ & $2.9(20)$ & $2.5(17)$ \\
\hline Urine $(\mathrm{n}=24)$ & $79.2(19)$ & $12.5(3)$ & $24.2(8)$ \\
\hline Swab or pus of infected skin lesion or abscess $(\mathrm{n}=33)$ & $33.3(11)$ & $36.4(12)$ & - \\
\hline CSF $(\mathrm{n}=12)$ & $91.7(11)$ & $8,3(1)$ & $(1)$ \\
\hline Other body fluids $(\mathrm{n}=8)$ & $62.5(5)$ & $25.0(2)$ & \\
\hline
\end{tabular}

\section{Antibiotic susceptibility testing}

In total, 27 Gram-negative isolates were available for susceptibility testing with VITEK ${ }^{\circledR} 2$. Among those, the resistance rates against commonly used antibiotics at the study site were: ampicillin/sulbactam 93.3\% $(n=21)$, cefotaxime $88.9 \%(n=24)$, ceftazidime $74.1 \%(n=20)$, cefipime $74.1 \%(n=20)$, ciprofloxacin $70.4 \%(n=19)$, and gentamicin $63.0 \%(n=17)$. Resistance rates against rarely used antibiotics was $48.1 \%(n=13)$ for piperacillin/tazobactam, and $7.4 \%(n=2)$ for meropenem. Only one case of amikacin resistance was detected among all 27 isolates (Table7).

\section{Resistance genes}

The overall frequencies of ESBL and carbapenemase genes detection among the isolated GNB were $81.5 \%(22 / 27)$ and $7.4 \%$ (2/27), respectively. In $55.6 \%$ of cases $(n=15)$, more than one ESBL gene was detected in the isolated GNB. The different ESBL were characterized as TEM ( $\mathrm{n}=17,77.3 \%), \mathrm{CTX}-\mathrm{M}-1$-group ( $n=15,68.2 \%)$, SHV-group ( $n=6,27.3 \%)$ and CTX-M-9-group ( $n=2,9.1 \%)$. Both, CTX-M-1-type and SHV-type were detected from 5/6 (83.3\%) of the $K$. pneumoniae isolates, whereas SHV-group was only detected in 1/13 of the E. coli isolates. In E. coli, only the CTX-M-1-group was common (see Table 8). Regarding carbapenemases, a single bla $\mathrm{NDM}-1_{1}$ from one isolated K. pneumoniae and a combination of bla ${ }_{\mathrm{NDM}-1}$ plus bla $_{\mathrm{OXA}-51}$ from an isolate of $A$. baumannii were detected.

\section{Effectiveness of empirical antibiotic treatment}

The results of the locally performed Kirby-Bauer disc diffusion test were available from 25 study participants with $E$. coli and $K$. pneumoniae isolates. Eighteen of these 25 study participants received an empirically initiated antibiotic treatment at the time of sampling. The Kirby-Bauer AST revealed high levels of resistance against commonly used antibiotics, rendering $72.2 \%(13 / 18)$ of the initiated antibiotic treatments ineffective. In particular, $72.0 \%(18 / 25)$ of the isolated GNB were resistant to $3 G C, 60.0 \%(15 / 25)$ to fluoroquinolones and $48.0 \%(12 / 25)$ to gentamicin. The results of the initial clinical evaluation, empirical antibiotic treatment and AST result according to Kirby-Bauer disc diffusion test are summarized below (Table 9).

Table 7. Antibiotic resistance rate of Gram-negative isolates

\begin{tabular}{|c|c|c|c|c|c|c|c|c|c|c|}
\hline $\begin{array}{l}\text { Bacterial } \\
\text { species }\end{array}$ & Ampicillin & $\begin{array}{l}\text { Ampicillin/ } \\
\text { sulbactam }\end{array}$ & Piperacillin & $\begin{array}{l}\text { Piperacillin/ } \\
\text { tazobactam }\end{array}$ & Cefotaxime & Ceftazidime & Cefepime & Meropenem & Amikacin & Gentar \\
\hline \multirow{2}{*}{$\begin{array}{l}\text { Escherichia } \\
\text { coli }(n=13)\end{array}$} & \multirow{2}{*}{$\begin{array}{l}92.3 \% \\
(12 / 13)\end{array}$} & $92.3 \%$ & $92.3 \%$ & $69.2 \%$ & $84.6 \%$ & $84.6 \%$ & $84.6 \%$ & $0 \%$ & $0 \%$ & $53.8 \%$ \\
\hline & & $(12 / 13)$ & $(12 / 13)$ & $(9 / 13)$ & $(11 / 13)$ & $(11 / 13)$ & $(11 / 13)$ & $(0 / 13)$ & $(0 / 13)$ & $(7 / 13)$ \\
\hline \multirow{2}{*}{$\begin{array}{l}\text { Klebsiella } \\
\text { pneumoniae } \\
(n=6)\end{array}$} & $100 \%$ & $100 \%$ & $100 \%$ & $50.0 \%$ & $100 \%$ & $100 \%$ & $100 \%$ & $16.7 \%$ & $16.7 \%$ & $83.3 \%$ \\
\hline & $(6 / 6)$ & $(6 / 6)$ & $(6 / 6)$ & $(3 / 6)$ & $(6 / 6)$ & $(6 / 6)$ & $(6 / 6)$ & $(1 / 6)$ & $(1 / 6)$ & $(5 / 6)$ \\
\hline \multirow{2}{*}{$\begin{array}{l}\text { Pseudomonas } \\
\text { aeruginosa }(n=4)\end{array}$} & \multirow[t]{2}{*}{-} & \multirow[t]{2}{*}{-} & $50.0 \%$ & $0 \%$ & $100 \%$ & $50.0 \%$ & $50.0 \%$ & $0 \%$ & $0 \%$ & $25.0 \%$ \\
\hline & & & $(2 / 4)$ & $(0 / 4)$ & $(4 / 4)$ & $(2 / 4)$ & $(2 / 4)$ & $(0 / 4)$ & $(0 / 4)$ & $(1 / 4)$ \\
\hline \multirow[t]{2}{*}{ Other $(n=4)$} & $75.0 \%$ & $75.0 \%$ & $75.0 \%$ & $25.0 \%$ & $75.0 \%$ & $25.0 \%$ & $25.0 \%$ & $25.0 \%$ & $0 \%$ & $50.0 \%$ \\
\hline & $(3 / 4)$ & $(3 / 4)$ & $(3 / 4)$ & $(1 / 4)$ & $(3 / 4)$ & $(1 / 4)$ & $(1 / 4)$ & $(1 / 4)$ & $(0 / 4)$ & $(2 / 4)$ \\
\hline \multirow[t]{2}{*}{ Total $(n=27)$} & $91.3 \%$ & $91.3 \%$ & $85.2 \%$ & $48.1 \%$ & $88.9 \%$ & $74.1 \%$ & $74.1 \%$ & $7.4 \%$ & $3.7 \%$ & $63.0 \%$ \\
\hline & $(21 / 23)$ & $(21 / 23)$ & $(23 / 27)$ & $(13 / 27)$ & $(24 / 27)$ & $(20 / 27)$ & $(20 / 27)$ & $(2 / 27)$ & $(1 / 27)$ & $(17 / 27$ \\
\hline
\end{tabular}

Others: Raoultella ornithinolytica $(\mathrm{n}=1)$; Raoultella planticola $(\mathrm{n}=1)$; Salmonella typhi $(\mathrm{n}=1)$; Acinetobacter baumannii $(\mathrm{n}=1)$

Table 8. Characterization and frequency of detected ESBL and carbapenemase genes among the Gram-negative isolates 


\begin{tabular}{|lllllllll|}
\hline Bacterial species & \multicolumn{2}{l}{$\begin{array}{l}\text { Resistance genes } \%(n) \\
\end{array}$} & & & & & CP genes \\
& ESBL genes & & & & \\
& All ESBL & CTX-M-1 group & TEM-group & SHV-group & CTX-M-9 group & All CP & NDM-1 & OXA-51 \\
\hline E. coli $(\mathrm{n}=13)$ & $92.3(12)$ & $69.2(9)$ & $76.9(10)$ & $7.7(1)$ & 0 & 0 & 0 & 0 \\
\hline K. pneumoniae $(\mathrm{n}=6)$ & $100(6)$ & $83.3(5)$ & $50.0(3)$ & $83.3(5)$ & 0 & $16.7(1)$ & $16.7(1)$ & 0 \\
\hline P. aeruginosa $(\mathrm{n}=4)$ & $50.0(2)$ & $25.0(1)$ & $50.0(2)$ & 0 & 0 & 0 & 0 & 0 \\
\hline Other* $(\mathrm{n}=4)$ & $75.0(3)$ & 0 & $50.0(2)$ & 0 & $50.0(2)$ & $25.0(1)$ & $25.0(1)$ & $25.0(1)$ \\
\hline All GNB $(\mathrm{n}=27)$ & $81.5(22)$ & $55.6(15)$ & $63.0(17)$ & $22.2(6)$ & $7.4(2)$ & $7.4(2)$ & $7.4(2)$ & $3.7(1)$ \\
\hline
\end{tabular}

*Other isolates: $R$. planticola $(\mathrm{n}=1)$ and $R$. ornithinolytica $(\mathrm{n}=1)$ : both positive for CTX-M-9 group; Salmonella Typhi ( $\mathrm{n}=1)$ : no ESBL- or CPE-production; and A. baumannii $(\mathrm{n}=1)$ : positive for OXA-51 and NDM-1

$\mathrm{CP}$, carbapenemase

Table 9. Clinical-evaluation, Kirby-Bauer AST result and empirical treatment of participants with E. coli or K. pneumoniae 


\begin{tabular}{|c|c|c|c|c|c|c|c|}
\hline \multirow{2}{*}{$\begin{array}{l}\text { Participant } \\
\text { No. }\end{array}$} & \multirow{2}{*}{$\begin{array}{l}\text { Bacterial } \\
\text { isolate }\end{array}$} & \multicolumn{3}{|c|}{ Resistance against } & \multirow[t]{2}{*}{ Clinical diagnosis } & \multirow{2}{*}{$\begin{array}{l}\text { Empirical antibiotic } \\
\text { treatment }\end{array}$} & \multirow{2}{*}{$\begin{array}{l}\text { Effectiveness of antibiotic } \\
\text { treatment }\end{array}$} \\
\hline & & $3 G C$ & Fluoroquinolones & Gentamicin & & & \\
\hline 20 & E. coli & Yes & Yes & No & UTI & Ciprofloxacin & Ineffective \\
\hline 56 & E. coli & Yes & No & Yes & RTI & Ceftriaxone, cloxacillin & Effective \\
\hline 258 & E. coli & No & Yes & Yes & AFI & None & - \\
\hline 259 & E. coli & Yes & Yes & Yes & AFI & None & - \\
\hline 264 & E. coli & Yes & No & No & SSTI & $\begin{array}{l}\text { Ceftriaxone, } \\
\text { metronidazole }\end{array}$ & Ineffective \\
\hline 272 & E. coli & Yes & Yes & Yes & SSTI & Cloxacillin & Ineffective \\
\hline 275 & E. coli & Yes & No & No & SSTI & $\begin{array}{l}\text { Ceftriaxone, } \\
\text { metronidazole }\end{array}$ & Ineffective \\
\hline 351 & E. coli & Yes & Yes & Yes & SSTI & $\begin{array}{l}\text { Ceftriaxone } \\
\text { metronidazole }\end{array}$ & Ineffective \\
\hline 411 & E. coli & Yes & Yes & Yes & AFI & None & - \\
\hline 423 & E. coli & No & Yes & Yes & RTI & None & - \\
\hline 432 & E. coli & Yes & Yes & Yes & RTI & $\begin{array}{l}\text { Azithromycin, } \\
\text { ceftriaxone }\end{array}$ & Ineffective \\
\hline 440 & E. coli & Yes & Yes & Yes & UTI & Ceftriaxone & Ineffective \\
\hline 483 & E. coli & Yes & Yes & No & AFI & $\begin{array}{l}\text { Azithromycin, } \\
\text { ceftriaxone }\end{array}$ & Ineffective \\
\hline 503 & E. coli & No & No & No & RTI & None & - \\
\hline 568 & E. coli & No & No & No & AFI & None & - \\
\hline 639 & E. coli & Yes & No & No & UTI & None & - \\
\hline 42 & $\begin{array}{l}\text { K. } \\
\text { pneumoniae }\end{array}$ & No & No & No & AFI & $\begin{array}{l}\text { Ceftriaxone, } \\
\text { gentamicin }\end{array}$ & Effective \\
\hline 59 & $\begin{array}{l}\text { K. } \\
\text { pneumoniae }\end{array}$ & No & No & No & RTI & $\begin{array}{l}\text { Ceftriaxone, } \\
\text { metronidazole }\end{array}$ & Effective \\
\hline 64 & $\begin{array}{l}\text { K. } \\
\text { pneumoniae }\end{array}$ & No & Yes & No & $\begin{array}{l}\text { Meningitis / } \\
\text { encephalitis }\end{array}$ & Ceftriaxone & Effective \\
\hline 278 & $\begin{array}{l}\text { K. } \\
\text { pneumoniae }\end{array}$ & Yes & Yes & Yes & SSTI & Ceftriaxone, cloxacillin & Ineffective \\
\hline 314 & $\begin{array}{l}\text { K. } \\
\text { pneumoniae }\end{array}$ & Yes & Yes & Yes & SSTI & $\begin{array}{l}\text { Ceftriaxone, } \\
\text { vancomycin }\end{array}$ & Ineffective \\
\hline 332 & $\begin{array}{l}\text { K. } \\
\text { pneumoniae }\end{array}$ & Yes & Yes & Not & AFI, sepsis & $\begin{array}{l}\text { Ceftriaxone, } \\
\text { gentamicin }\end{array}$ & Effective \\
\hline 545 & $\begin{array}{l}\text { K. } \\
\text { pneumoniae }\end{array}$ & Yes & Yes & Yes & UTI & $\begin{array}{l}\text { Tuberculostatic } \\
\text { treatment }\end{array}$ & Ineffective \\
\hline 677 & $\begin{array}{l}\text { K. } \\
\text { pneumoniae }\end{array}$ & Yes & Not & No & RTI & $\begin{array}{l}\text { Ceftazidime, } \\
\text { vancomycin }\end{array}$ & Ineffective \\
\hline 681 & $\begin{array}{l}\text { K. } \\
\text { pneumoniae }\end{array}$ & Yes & Yes & No & RTI & $\begin{array}{l}\text { Ceftriaxone, } \\
\text { vancomycin }\end{array}$ & Ineffective \\
\hline
\end{tabular}

3GC: $3^{\text {rd }}$ generation cephalosporin; UTI: Urinary tract infection; RTI: respiratory tract infection; AFI: Acute febrile illness (febrile disease with unknown source); SSTI: skin and soft tissue infection;

\section{Discussion}

To date, infectious disease are one of the most common causes of morbidity and mortality in resource-limited settings such as Ethiopia (1), but the availability of epidemiological data about causative pathogens and distribution of AMR remains limited. In this study, we found a high rate of MDR in GNB isolated from febrile patients. As previously described from Uganda, MDR GNB are the main cause of sepsis in febrile cancer patients with more than $50 \%$ of the sepsis episodes being caused by E. coli infections (15). Similar to these findings and to the findings of Wasihun et al. (2015) and Moges et al. (2021) from northern Ethiopia $(16,17)$, E. coli was the most prevalent isolated GNB in our study.

The culture positivity rate of $5.4 \%$ from blood cultures was low, which might partially be explained by the fact that the causative pathogen was non-cultivable in a proportion of patients (haemoparasites, viruses, or non-cultivable bacteria). Similar findings were reported from South Africa (18). In patients with febrile 
illness with unknown source of infection in comparison to other clinical diagnoses, the likelihood of positive blood cultures was lowest. The highest yield of bacterial cultures was reported from swabs in patients with SSTI. There was a trend of a decreased or elevated leucocyte count or an increased CRP level to being associated with blood culture positivity. However, these associations were not significant and the predictive value of these parameters to guide blood culture diagnostics is insufficient. Thus, our finding strengthens a previous report from Italy that CRP level alone is not sufficient to predict blood culture positivity (19). In this time of wide-spread AMR and the associated risk of failing antibiotic therapies, blood culture diagnostics are essential to guide management of bacterial infections. If the broad application of blood culture diagnostics is not possible due to resource limitations, the application of other parameters such as procalcitonin or monocyte distribution width (MDW) could help to guide the rational use of blood cultures (20,21).

In our study, the resistance rates of isolated GNB against commonly used antibiotics was high, severely confining the effectiveness of aminopenicillins in combination with betalactamase-inhibitors or $3 \mathrm{GC}$ for empirical treatment of infections possibly caused by GNB. The lowest resistance rates were found for the carbapenem meropenem and amikacin. These results are consistent with the results of other recently published data from different parts of Ethiopia, in particular from Addis Ababa (11,22), Jimma (23) and Bahir Dar (10). The different resistance rates to certain antibiotics reflect the frequency of antibiotic prescriptions. While aminopenicillins and 3GCs are applied very frequently, carbapenems are hardly used due to their high cost and limited availability. Of note, while the resistance rate for amikacin was very low, many of the isolated GNB were resistant to gentamicin. This difference might be explained by the frequent application of gentamicin at the study center. In contrast, amikacin is virtually not applied at all $(24,25)$.

Our data revealed overall frequencies of ESBL and carbapenemase production of $81.5 \%$ and $7.4 \%$ among the isolated GNB, respectively. Of note, all isolates of K. pneumoniae were ESBL-positive. These findings are consistent with recently published data from other parts of Ethiopia, where $K$. pneumoniae has also been shown to be the most common ESBL-expressing pathogen, followed by $E$. coli $(10,11,22)$.

Regarding the characterization of ESBL genes among the Gram-negative isolates in our study, TEM-type and CTX-M-1-type were most common, followed by SHV-type and least frequently CTX-M-9-type. CTX-M-2 and CTX-M-8/25 were not detected at all. Compared to TEM-type and SHV-type, CTX-M-type enzymes are more widely disseminated world-wide and many variants associated with clinically relevant functional heterogeneity have been described. Thus, coexpression of different ESBL types is more common among GNB which harbor CTX-M-type enzymes (26).

Both, CTX-M-1 group and SHV-group were abundantly detected in K. pneumoniae, whereas in E. coli the SHV-group was detected only in $8 \%$ of the isolates (Table 8). This finding matches the report by Ogutu et al. that SHV-type is the predominant ESBL enzyme in K. pneumoniae and TEM-type is the most prevalent in E. coli (27).

A single $b / a_{\mathrm{NDM}-1}$ carbapenemase gene in a $K$. pneumoniae isolate and $b / a_{\mathrm{NDM}-1}$ plus bla $a_{0 \mathrm{XA}-51}$ carbapenemase genes in an $A$. baumannii isolate were detected. The expression of a bla $a_{\mathrm{NDM}-1}$ in an $A$. baumannii isolate has previously been reported from the southwestern part of Ethiopia (28), but to our knowledge no case of of bla $a_{\mathrm{NDM}-1}$ presence in $K$. pneumoniae has been reported to date. In general, this finding is not surprising since the bla ${ }_{\mathrm{NDM}-1}$ carbapenemase gene in K. pneumoniae and A. baumannii have been commonly reported from other eastern African countries like Kenya, Uganda (29), Egypt (30) and Sudan (31).

In this study, most of the antibiotics initiated by the treating physicians for empirical treatment in the participating patients were ineffective according to the AST. However, these data have to be interpreted with caution since mostly microbiological culturing was performed after initiation of empirical antibiotic therapy and evaluation of the clinical success rate of the empirically initiated antibiotic therapies was not part of this investigation. Nevertheless, antibiotic resistance impairing the success of empirical antibiotic therapies seems alarmingly common and local epidemiological resistance data should be taken into account before initiation of antibiotic therapy (32). An adaptation of the local empiric antibiotic therapy strategy could be all the more necessary as the excessive use of $3 \mathrm{GC}$ could be one of the main reasons for the spread of ESBL-producing bacteria (33).

Selectively utilizing antibiotics based on the AST result is not only favorable for optimal treatment success but it also plays a major role in combating the spread of MDR bacteria. Adequate microbiological culturing before initiation of empirical antibiotic treatment is necessary to enable AST-based antibiotic therapy. As resources are limited and supply of laboratory materials is unreliable at the study site as at many other sites in low-income countries, it may not always be possible to perform comprehensive microbiological testing. In such cases, at least surveillance studies with the subsequent establishment of resistance statistics should be carried out to enable calculated antibiotic therapies adapted to the local resistance status. This might help to reduce the imprudent use of antibiotics (8).

A limitation of this study might be an impaired sensitivity of blood cultures, since only one set of locally prepared blood culture bottles was used for blood culturing. The limited availability and high cost of commercially available blood culture bottles prevent the regular use of such products on site. The molecular resistance testing was not possible for all Gram-negative isolates due to loss upon storage and transport. Our study did not investigate whether infections caused by ESBL- or carbapenemase-producing GNB were associated with reduced success of antibiotic therapies or increased mortality.

\section{Conclusion}

In this study performed at a tertiary hospital in Ethiopia, we isolated GNB from patients with infectious diseases with high rates of MDR including 3GCresistance, which are the most commonly used substances for empirical antibiotic treatment. Thus, $72 \%$ of the initiated antibiotic therapies in this cohort should be considered ineffective according to AST. As an underlying cause for extensive drug resistance, we found a high prevalence of different ESBL enzymes with predominance of TEM- and CTX-M-1-types. More than half of Gram-negative isolates carried two or more resistance ESBL genes. In addition, carbapenemases were detected in as many as $7.4 \%$ of the Gram-negative isolates, despite the limited availability and rare application of carbapenems in the country. These findings emphasize the need for regular microbiological investigation of appropriate specimen before initiation of empirical antibiotic treatment wherever possible. In resource-limited settings like Ethiopia with confined capacities for regular microbiological investigation, local and national 
programs for MDR surveillance might be helpful to reduce the futile use of antibiotics and improve the treatment outcome of calculated antibiotic therapies. The implementation of new strategies like MDW- or PCT-guided culturing could help to enable the resource-saving use of microbiological culture methods. Strengthening of antimicrobial stewardship programs and appropriate policies to regulate the use of antibiotics and to monitor the emergence of resistant bacteria is thus needed without delay.

\section{Declarations}

\section{Funding}

The first author of this study, Tafese Beyene Tufa, was supported with stipends by the Bayer Foundation Talents for Africa Scholarship Program and by the Heinz Ansmann Foundation for AIDS research. There was no influence of the funding organization on analysis or interpretation of the described data.

\section{Acknowledgments}

The authors thank the study and laboratory team of the Hirsch Institute of Tropical Medicine in Asella, Ethiopia and the staff of the Institute of Medical Microbiology and Hospital Hygiene, Heinrich Heine University, Düsseldorf, Germany for supporting this work.

Ethics approval and consent to participate

The appropriate ethical review boards of Arsi University, Ethiopia (reference number A/U/H/S/C/120/6443/2017), the Oromia Regional Health Bureau, Ethiopia (reference number BEFO/AHBTFH/1-8/2017), and Düsseldorf University Hospital, Germany (reference number 5729) approved the study. The ethical clearance for sample transportation between Ethiopia and Germany was obtained from the National Ethical Review Board of the Ethiopian Ministry of Science and Technology (reference number 310/204/2017). Before the start of study procedures, written informed consent to participate in the study was obtained from each study participant or, in the case of minors, from their legal guardians.

\section{Consent for publication}

The informed consent signed by each study participant or, in the case of minors, from their legal guardians, contained the consent for publication of anonymized data.

\section{Availability of data and material}

All relevant data generated or analyzed during this study are included in this article.

\section{Competing interests}

The authors declare that they have no competing interests.

\section{Authors' contributions}

Tafese Beyene Tufa: Conception and design, performance of laboratory investigations acquisition, analysis, and interpretation of data, drafting of the manuscript and approval of the manuscript for publication

Colin Mackenzie: Interpretation of data, critical revision of the manuscript and approval of the manuscript for publication

Hans Martin Orth: Conception and design, revision of the manuscript and approval of the manuscript for publication

Tobias Wienemann: supervise the laboratory investigations, interpret the results and approval of the manuscript for publication

Tamara Nordmann: Conception and design, revision of the manuscript and approval of the manuscript for publication

Sileshi Abdissa: Performance of laboratory investigations and approval of the manuscript for publication

Zewdu Hurissa: Interpretation of data, revision of the manuscript and approval of the manuscript for publication

Andreas Schönfeld: Conception and design, revision of the manuscript and approval of the manuscript for publication

Matthias Bosselmann: Conception and design, revision of the manuscript and approval of the manuscript for publication

Dieter Häussinger: Interpretation of data, critical revision of the manuscript and approval of the manuscript for publication

Klaus Pfeffer: Interpretation of data, critical revision of the manuscript and approval of the manuscript for publication

Tom Luedde: critical revision of the manuscript and approval of the manuscript for publication

André Fuchs: Conception and design, acquisition and interpretation of the data, revision of the manuscript and approval of the manuscript for publication Torsten Feldt: Conception and design, interpretation and analysis of data, critical revision of the manuscript and approval of the manuscript for publication 


\section{References}

1. Misganaw A, Haregu TN, Deribe K, Tessema GA, Deribew A, Melaku YA, Amare AT, Abera SF, Gedefaw M, Dessalegn M, Lakew Y, Bekele T, Mohammed M, Yirsaw BD, Damtew SA, Krohn KJ, Achoki T, Blore J, Assefa Y, Naghavi M. National mortality burden due to communicable, non-communicable, and other diseases in Ethiopia, 1990-2015: findings from the Global Burden of Disease Study 2015. Popul Health Metr. 2017;15:29.

2. Alosaimy S, Jorgensen SCJ, Lagnf AM, Melvin S, Mynatt RP, Carlson TJ, Garey KW, Allen D, Venugopalan V, Veve M, Athans V, Saw S, Yost CN, Davis SL, Rybak MJ. Real-world Multicenter Analysis of Clinical Outcomes and Safety of Meropenem-Vaborbactam in Patients Treated for Serious Gram-Negative Bacterial Infections. Open Forum Infect Dis. 2020;7:ofaa051.

3. CDC. 2019. Antibiotic Resistance Threats in the United States. Atlanta, GA: US Department of Health and Human Services, CDC; 2019 wwwcdcgov/DrugResistance/Biggest-Threatshtml.

4. Ruppé É, Woerther PL, Barbier F. Mechanisms of antimicrobial resistance in Gram-negative bacilli. Ann Intensive Care. 2015;5:61.

5. Bevan ER, Jones AM, Hawkey PM. Global epidemiology of CTX-M $\beta$-lactamases: temporal and geographical shifts in genotype. J Antimicrob Chemother. 2017;72:2145-55.

6. Martínez-Martínez L, González-López JJ. Carbapenemases in Enterobacteriaceae: types and molecular epidemiology. Enferm Infecc Microbiol Clin. 2014;32(Suppl 4):4-9.

7. Lester R, Musicha P, van Ginneken N, Dramowski A, Hamer DH, Garner P, Feasey NA. Prevalence and outcome of bloodstream infections due to thirdgeneration cephalosporin-resistant Enterobacteriaceae in sub-Saharan Africa: a systematic review. J Antimicrob Chemother. 2020;75:492-507.

8. Leekha S, Terrell CL, Edson RS. General principles of antimicrobial therapy. Mayo Clin Proc. 2011;86:156-67.

9. Fuchs A, Tufa TB, Hörner J, Hurissa Z, Nordmann T, Bosselmann M, Abdissa S, Sorsa A, Orth HM, Jensen BO, MacKenzie C, Pfeffer K, Kaasch AJ, Bode JG, Häussinger D, Feldt T. Clinical and microbiological characterization of sepsis and evaluation of sepsis scores. PLoS One. 2021;16:e0247646.

10. Moges F, Eshetie S, Abebe W, Mekonnen F, Dagnew M, Endale A, Amare A, Feleke T, Gizachew M, Tiruneh M. High prevalence of extended-spectrum betalactamase-producing Gram-negative pathogens from patients attending Felege Hiwot Comprehensive Specialized Hospital, Bahir Dar, Amhara region. PLoS One. 2019;14:e0215177.

11. Beyene D, Bitew A, Fantew S, Mihret A, Evans M. Multidrug-resistant profile and prevalence of extended spectrum $\beta$-lactamase and carbapenemase production in fermentative Gram-negative bacilli recovered from patients and specimens referred to National Reference Laboratory, Addis Ababa, Ethiopia. PLoS One. 2019;14:e0222911.

12. Strauß LM, Dahms C, Becker K, Kramer A, Kaase M, Mellmann A. Development and evaluation of a novel universal $\beta$-lactamase gene subtyping assay for blaSHV, blaTEM and blaCTX-M using clinical and livestock-associated Escherichia coli. J Antimicrob Chemother. 2015;70:710-5.

13. Wendel AF, Brodner AH, Wydra S, Ressina S, Henrich B, Pfeffer K, Toleman MA, Mackenzie CR. Genetic characterization and emergence of the metallo- $\beta$ lactamase GIM-1 in Pseudomonas spp. and Enterobacteriaceae during a long-term outbreak. Antimicrob Agents Chemother. 2013;57:5162-5.

14. Huang XZ, Cash DM, Chahine MA, Nikolich MP, Craft DW. Development and validation of a multiplex TaqMan real-time PCR for rapid detection of genes encoding four types of class D carbapenemase in Acinetobacter baumannii. J Med Microbiol. 2012;61:1532-7.

15. Lubwama M, Phipps W, Najjuka CF, Kajumbula H, Ddungu H, Kambugu JB, Bwanga F. Bacteremia in febrile cancer patients in Uganda. BMC Res Notes. 2019;12:464.

16. Wasihun AG, Wlekidan LN, Gebremariam SA, Dejene TA, Welderufael AL, Haile TD, Muthupandian S. Bacteriological profile and antimicrobial susceptibility patterns of blood culture isolates among febrile patients in Mekelle Hospital, Northern Ethiopia. Springerplus. 2015;4:314.

17. Moges F, Gizachew M, Dagnew M, Amare A, Sharew B, Eshetie S, Abebe W, Million Y, Feleke T, Tiruneh M. Multidrug resistance and extended-spectrum beta-lactamase producing Gram-negative bacteria from three Referral Hospitals of Amhara region, Ethiopia. Ann Clin Microbiol Antimicrob. $2021 ; 20: 16$.

18. Boyles TH, Davis K, Crede T, Malan J, Mendelson M, Lesosky M. Blood cultures taken from patients attending emergency departments in South Africa are an important antibiotic stewardship tool, which directly influences patient management. BMC Infect Dis. 2015;15:410.

19. Bassetti M, Russo A, Righi E, Dolso E, Merelli M, Cannarsa N, D'Aurizio F, Sartor A, Curcio F. Comparison between procalcitonin and C-reactive protein to predict blood culture results in ICU patients. Crit Care. 2018;22:252.

20. Polilli E, Sozio F, Frattari A, Persichitti L, Sensi M, Posata R, Di Gregorio M, Sciacca A, Flacco ME, Manzoli L, Di lorio G, Parruti G. 2020. Comparison of Monocyte Distribution Width (MDW) and Procalcitonin for early recognition of sepsis. PLoS One 15:e0227300.

21. Crouser ED, Parrillo JE, Seymour C, Angus DC, Bicking K, Tejidor L, Magari R, Careaga D, Williams J, Closser DR, Samoszuk M, Herren L, Robart E, Chaves F. Improved Early Detection of Sepsis in the ED With a Novel Monocyte Distribution Width Biomarker. Chest. 2017;152:518-26.

22. Teklu DS, Negeri AA, Legese MH, Bedada TL, Woldemariam HK, Tullu KD. Extended-spectrum beta-lactamase production and multi-drug resistance among Enterobacteriaceae isolated in Addis Ababa, Ethiopia. Antimicrob Resist Infect Control. 2019;8:39.

23. Abayneh M, Tesfaw G, Abdissa A. 2018. Isolation of Extended-Spectrum $\beta$-lactamase- (ESBL-) Producing Escherichia coli and Klebsiella pneumoniae from Patients with Community-Onset Urinary Tract Infections in Jimma University Specialized Hospital, Southwest Ethiopia. Can J Infect Dis Med Microbiol 2018:4846159.

24. Kettner M, Krćméry V. Development of gentamicin resistance in gram-negative bacteria in Czechoslovakia and correlation with its usage. Drugs Exp Clin Res. 1988;14:511-7.

25. Wang R, Yang Q, Zhang S, Hong Y, Zhang M, Jiang S. Trends and correlation of antibiotic susceptibility and antibiotic consumption at a large teaching hospital in China (2007-2016): a surveillance study. Ther Clin Risk Manag. 2019;15:1019-27. 
26. D'Andrea MM, Arena F, Pallecchi L, Rossolini GM. CTX-M-type $\beta$-lactamases: a successful story of antibiotic resistance. Int J Med Microbiol. 2013;303:305-17.

27. Ogutu JO, Zhang Q, Huang Y, Yan H, Su L, Gao B, Zhang W, Zhao J, Cai W, Li W, Zhao H, Chen Y, Song W, Chen X, Fu Y, Zhang F. Development of a multiplex PCR system and its application in detection of blaSHV, blaTEM, blaCTX-M-1, blaCTX-M-9 and blaOXA-1 group genes in clinical Klebsiella pneumoniae and Escherichia coli strains. J Antibiot (Tokyo). 2015;68:725-33.

28. Pritsch M, Zeynudin A, Messerer M, Baumer S, Liegl G, Schubert S, Löscher T, Hoelscher M, Belachew T, Rachow A, Wieser A. First report on bla (NDM-1)producing Acinetobacter baumannii in three clinical isolates from Ethiopia. BMC Infect Dis. 2017;17:180.

29. Ssekatawa K, Byarugaba DK, Wampande E, Ejobi F. A systematic review: the current status of carbapenem resistance in East Africa. BMC Res Notes. 2018;11:629.

30. Khalil MAF, Elgaml A, El-Mowafy M. Emergence of Multidrug-Resistant New Delhi Metallo- $\beta$-Lactamase-1-Producing Klebsiella pneumoniae in Egypt. Microb Drug Resist. 2017;23:480-7.

31. Adam MA, Elhag WI. Prevalence of metallo- $\beta$-lactamase acquired genes among carbapenems susceptible and resistant Gram-negative clinical isolates using multiplex PCR, Khartoum hospitals, Khartoum Sudan. BMC Infect Dis. 2018;18:668.

32. Montravers P, Dupont H, Gauzit R, Veber B, Bedos JP, Lepape A. Strategies of initiation and streamlining of antibiotic therapy in 41 French intensive care units. Crit Care. 2011;15:R17.

33. Goyal D, Dean N, Neill S, Jones P, Dascomb K. Risk Factors for Community-Acquired Extended-Spectrum Beta-Lactamase-Producing Enterobacteriaceae Infections-A Retrospective Study of Symptomatic Urinary Tract Infections. Open Forum Infect Dis. 2019;6:ofy357.

\section{Figures}

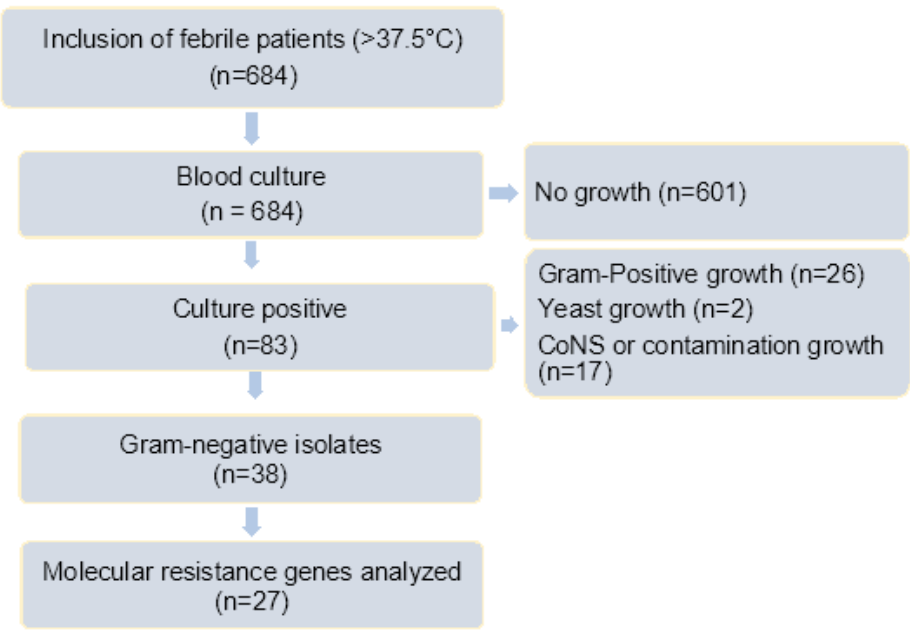

\section{Figure 1}

Flow diagram of participants' inclusion 